\title{
"Ela só quer jogar o futebol dela": quando meninas brincam e tensionam a supremacia masculina e as expectativas de gênero juntos aos meninos no espaço da escola
}

\begin{abstract}
Resumo: Este artigo procura realizar algumas reflexões sobre os gestos de resistência e transgressões de meninas de 7 anos de idade contra as normatizações machistas heteropatriarcais que impõem determinadas posturas, execução de brincadeiras e restringe o uso de espaços sociais para os diferentes sujeitos. Trata-se de uma pesquisa realizada na escola, nos Anos Iniciais do Ensino Fundamental, construída com base no pensamento feminista e os estudos da criança e da infância, buscando a ampliação de nossas percepções a respeito das culturas infantis produzidas pelas crianças que com suas práticas, experiências, criações, invenções e movimentos tensionam as tramas do sexismo e machismo presentes na sociedade.
\end{abstract}

Palavras-chave: Relações de gênero. Feminismo. Culturas infantis. Ensino Fundamental.

O problema da questão de gênero é que ela prescreve como devemos ser em vez de reconhecer como somos. Seríamos bem mais felizes, mais livres para sermos quem realmente somos se não tivéssemos o peso das expectativas do gênero.

(ADICHIE, 2008, p. 42-43).
Artur Oriel Pereira

Universidade Estadual de Campinas (Unicamp)

arturoriel@gmail.com

\section{Introdução}

Nesses últimos anos, o cenário brasileiro vem estabelecendo um avanço conservador na esfera política, principalmente, por parte dos grupos contrários as pautas ligadas aos direitos sociais das minorias. Disputas e conflitos entre diversos grupos e setores sociais aumentaram, assim, as polêmicas referentes à discussão da temática das relações de gênero e sexualidade na educação básica brasileira recaem sobre os direitos sociais dos diferentes sujeitos, a qualidade da educação das crianças e as políticas educacionais.

Todavia, não podemos ignorar que tal cenário, também reflete paulatinamente os ganhos das lutas feministas, das reivindicações do movimento LGBTs (Lésbicas, Gays, Bissexuais, Transexuais e Trangêneros) e das produções de estudos e investigações sobre esta temática no campo acadêmico. E apesar do crescimento contínuo da perspectiva de gênero e diversidade na produção acadêmica 
em diferentes áreas de conhecimento. Na educação, em especial, precisamos aprofundar as discussões sobre as infâncias e culturas infantis produzidas pelas meninas e meninos que com suas práticas, experiências, criações, invenções, movimentos de resistências contra a colonização do seu mundo pelos adultos, tensionam as tramas do sexismo e machismo.

É com base neste prisma que este artigo, propõe algumas reflexões sobre as potencialidades transgressoras de meninas com sete anos de idade contra as normatizações heteropatriarcais no espaço dos anos iniciais do ensino fundamental.

\section{Construindo caminhos com as crianças: procedimentos metodológicos}

Pela natureza do objeto, esta investigação foi desenvolvida em uma escola pública da rede municipal de ensino, localizada em um bairro de operários(as) na região leste da cidade de São Paulo. No entorno da escola, há residências construídas de forma planejada, com ruas largas e com grande quantidade de praças, por essa razão, o bairro torna-se um dos mais arborizados do município. As famílias das crianças matriculadas nessa escola, em sua maioria, residem no bairro e trabalham em outra região da cidade.

As crianças aqui representadas formam um grupo infantil de 25 crianças matriculadas no $2^{\circ}$ ano do Ensino Fundamental I. A ideia é trazer a visibilidade para as potencialidades criativas e a diversidade, das meninas e dos meninos.

Sigo o que está previsto na Lei que resguarda os direitos das crianças e adolescentes (Estatuto da Criança e do Adolescente - ECA, Lei n. ${ }^{\circ}$ 8.069/1990) e o que está previsto na Resolução CNS/MS $n^{0} 466 / 2012$ e suas complementares a respeito da ética em pesquisa com seres humanos e que resguarda os direitos das(os) participantes. Dessa maneira, preservo suas identidades, bem como não identifico o nome da escola.

Tabela 1: 0 grupo infantil

\begin{tabular}{|l|l|l|l|l|l|}
\hline \multicolumn{3}{|c|}{ Meninas } & \multicolumn{3}{c|}{ Meninos } \\
\hline Idade & Negras & Brancas & Idade & Negros & Brancos \\
\hline 7 anos & 2 & 9 & 7 anos & 3 & 11 \\
\hline Total & 11 & Total & 14 \\
\hline
\end{tabular}

Fonte: elaborada pelo autor (2018). 
Não houve a necessidade de deslocamento das(os) participantes, pois o acompanhamento das atividades ocorreu durante os diferentes momentos de horário escolar na sala de aula, refeitório, recreio, parque e outros espaços da escola.

Destaco a composição multiétnica e racial das(os) filhas(os) da classe trabalhadora que frequentam essa escola pública municipal, assim, convêm ressaltar que "classe" e "raça" não se contrapõem, mas se entrelaçam como elementos dinâmicos. Como aponta Fernandes (1998, p. 5), "[...] se a classe tem de ser forçosamente o componente hegemônico, nem por isso a raça atua como um dinamismo coletivo secundário. [...] Classe e raça se fortalecem reciprocamente e combinam forças centrífugas à ordem existente". Desse modo, a análise desses marcadores sociais também demanda uma reflexão sobre a presença da criança imigrante na escola como elemento de peso no processo de discriminação racial e das desigualdades sociais.

A multiplicidade étnica é um elemento importante porque algumas formas de discriminação geralmente combinam os elementos raciais, fisionômicos e de nacionalidade e implicam, por exemplo, que imigrantes com traços negros sofram mais com a discriminação do que imigrantes com traços brancos. Em outras palavras, como destaca Ianni (2004, p. 12-17), esse aspecto "[...] implica uma escala de preconceitos, isto é, alguns são mais discriminados do que outros, [...] trata-se de como as relações sociais estão fabricando continuamente o outro", em uma sociedade competitiva que permanece injusta, com desigualdade social extrema, e que articula o preconceito, como técnica de poder e de dominação.

Em diferentes momentos do horário escolar, como parte do dia a dia, as meninas e os meninos compartilharam suas experiências. Muitas vezes, as crianças conversaram sobre os jogos e as brincadeiras, os estudos do meio que foram realizados nos jardins, em espaços arborizados e no parque da escola, algumas atividades que aconteceram durante as aulas de educação física, como também a observação das suas relações com outras(os) professoras(es) e seus familiares. Esse conhecimento foi, e é, construído na interação entre todas(os), aberto a possibilidade de conhecer e conhecer-se, para além do currículo escolar e dos pertencimentos culturais.

O contexto escolar é capaz de proporcionar ações, práticas e interações que dinamizam as vivências e experiências de meninas e meninos ao produzirem culturas. Nesse processo de pesquisa 
surgiram indagações que revelam muitos desafios. Entre eles, a reflexão de como ser professor-pesquisador e como tornar objeto de estudo as manifestações das meninas e meninos frente as normatizações heteropatriarcais no cotidiano da minha turma.

A noção de ser "professor-pesquisador", ligada ao tipo de pesquisa "própria" dessa profissão, assim como "os problemas levantados pelopróprio professor ao longo de sua experiência docente" é um campo que vem sendo debatido há algum tempo na academia científica. (LÜDKE, 2001, p. 77)

Tratar dos dilemas e das perspectivas na relação entre ensino e pesquisa, que defende a ideia da prática de pesquisa na formação de professoras e professores, compreendendo que, por meio dela, esses(as) profissionais podem se tornar autônomos(as) e críticos(as), capazes de trabalhar com rigorosidade os problemaspor eles(as) levantados, ao exercitarem, no processo de pesquisa, a observação, oregistro, o planejamento de novas ações e abordagens com base nos dados analisados pelaliteratura aprofundada no estudo. (SANTOS, 2012)

É um desafio que transpõe a separação entre teoria e prática, entre o professor na escola e o pesquisador na universidade, "COnectando teoria e prática para superar tantoa ideia de uma ordem hierárquica quanto a ideia de prática como tradução operacional das teorias "sistematizadas. (INFANTINO; ZUCCOLI, 2016, p. 44-45) Em virtude disso, acredito quea identidade nesse sentido não é vista em termos abstratos, mas em contextos, em relação às crianças, mas também com a própria formação pessoal, profissional e educacional, além da experiência. (RINALDI, 2012)

Utilizo nesse estudo a concepção de "pesquisa participante" que a define como "aquela em que o pesquisador, para realizar a observação dos fenômenos, compartilha a vivência dos sujeitos pesquisados, participando, de forma sistemática e permanente, ao longo do tempo da pesquisa, das suas atividades". (SEVERINO, 2007, p. 120) Esta opção metodológica assumida traz meu exercício contínuo de pesquisador diante da realidade observada e com ela o ato de aproximar e distanciar-me, para que, nesse movimento, os sujeitos (meninas e meninos) e o objeto desta pesquisa (relações de gênero na infância) pudessem estar conectados aos seus contextos, sendo compreendido, como uma "teia" complexa de relações, que envolve o tempo histórico e o espaço social. 
O entrosamento com a turma foi fundamental, porque a análise dos dados levou em conta as infâncias vividas e as práticas interpretadas a partir das crianças. Como professor-pesquisador, realizando observação participante, procurei, neste movimento da pesquisa com as crianças, o estranhamento da minha própria prática, a respeito da concepção de educar, brincar e cuidar, bem como da tríade ler, escrever e fazer contasque, precocemente permeia o processo educativo das crianças. Passei a pensar "o quê" as crianças vêm construindono interior das culturas infantis no espaço da escola.

A organização dos registros da pesquisa - por meio do Diário de Campo, permitiu que, em cada situação compartilhada com as crianças e nas conversas que eram tecidas nos diversos espaços da escola, as meninas e os meninos fossem observados(as) com a intenção de coletarsuas falas e interações.

\section{As potencialidades criativas e transgressoras de meninas e meninos no interior das culturas infantis}

Nesta seção, apresento a análise dos dados, utilizando trechos do Diário de Campo com o objetivo de ampliar percepções a respeito das culturas infantis produzidas por meninas e meninos que com suas práticas, experiências, criações, invenções e movimentos tensionam as tramas do sexismo e machismo.

Nos espaços da escola é possível ver as crianças reproduzindo-interpretando ideias, artefatos, costumes, leis, crenças morais e conhecimento, adquiridos por meio do convívio social, conforme seus desejos e intencionalidades, em um processo de apreensão ativoda cultura maior, em uma atividade criadora que carrega a complexidade das relações experienciadas entre os pares e os(as) adultos(as).

Este conceito de reprodução interpretativa cunhado por Corsaro (2011) tendo como referência teórica Geertz (2008) traz a concepção que as crianças não se limitam a internalizar aspectos da sociedade, mas, contribuem ativamente para a produção de mudanças sociais, mesmo estando, por sua própria ação, restritas pela estrutura social.

Quando elas brincam, as atividades podem ser efetuadas de diferentes maneiras, objetos inanimados podem ser tratados como animados, bem como podem executar uma atividade normalmenterealizada por um adulto, dessa forma intentam resolver algu- 
(1) O atleta brasileiro Neymar da Silva Santos Júnior atua como ponta-esquerda defendendo a

Seleção Brasileira na Copa do Mundo de Futebol 2018. É um dos profissionais do futebol mais famosos do mundo. Disponível em: https://esportes.estadao. com.br/noticias/futebol,imprensabritanica-critica-neymar-mimadoresmungao-dramatico-etrapaceiro,70002362167 Acesso em: 22 jun. 2018. mas incertezas advindas dassuas interações com o mundo adulto compartilhando-as com os colegas. (FERNANDES, 2004)

Com base no referencial teórico supracitado, apresento a decisão estratégica de Manu, que, de certa maneira, subverte as regras adultas do futebol profissional com padrão androcêntrico por meio de ajustes secundários. Nos termos de Corsaro (2011) e Goffman (1961), com uma disposição habitual ela mobiliza significados não autorizados no interior da organização do grupo infantil, contorna elementos da organização sobre o que deve ser feito ou deveria ser feito; quer isto dizer, por meiode uma ação construída de forma cooperativa com o grupo, por alguns instantes, ela tensiona as práticas e obtém "controle" de sua vida:

$\mathrm{Na}$ sala de aula, a turma do $2^{\circ}$ ano dos anos iniciais do ensino fundamental está eufórica com os jogos da Copa do Mundo de Futebol FIFA (Federação Internacional de Futebol Associação). As crianças conversam uma com os outras sobre o que fizeram com seus familiares no dia de jogo da seleção brasileira. Falam sobre o desempenho e comportamento do jogador Neymar ${ }^{1}$, atacante da seleção, que tem sido alvo de críticas quanto a sua atuação nos jogos e o seu comportamento debochado com a imprensa.Também discutem acerca de algumas atividades educativas realizadas com os (as) seus (suas) professores(as). Em seguida, como parte do cronograma, vamos ao parque da escola, aproveitar o Sol que tão logo perderá sua intensidade com o final da tarde e a chegada inverno. Meninas e meninos correm de um lado para o outro, brincam de pegapega e pique-esconde. Brinquedos estão espalhados no chão de cimento, no gramado, próximo às flores e aos arbustos que compõem esse espaço. Brincam no escorregador, no conjunto de pneus empilhados, nas balanças. Alguns meninos sobem nas grades de ferro ao lado do muro da escola para ver as pessoas que passam na rua. Sentado em um banco, observo os movimentos das crianças e de suas brincadeiras, até que em um dado momento, vejo um grupo formado por cinco meninos e uma menina, o que me desperta ainda mais a atenção. Percebo que essas crianças estão brincando de jogar futebol. A menina organiza quem deve chutar a bola e para quem. Em alguns momentos, com a bola sobre os pés, determina que os meninos fiquem parados, um ao lado do outro, como uma barreira humana, esperando suas orientações. Tempos depois, os meninos começam a reclamar. Até que Fabrício e Diego, dois deles, visivelmente transtornados, vêm na minha direção. Diego começa chorar e comenta: 'Professor, é a Manu. Ela só 
quer jogar o futebol dela!". Olhando-os com ternura bem como para a menina e os demais meninos que estão discutindo; pergunto qual é o problema. Prontamente, Fabricio, o mais calmo, explica que Manu mudou as regras de futebol e que está "mandando em tudo!! Então, peço que ele me diga como são as regras de futebol. Entusiasmado, ele me explica que teríamos que dividir as pessoas do grupo, metade de um lado e outra metade do outro, que o jogo é um contra o outro, e que não devemos utilizar a bola com as mãos, mas 'Manu não quer assim!', enfatiza Diego. Já nos observando de longe, Manu solta um grito: 'Professor, os meninos são chatos demais, não sabem brincar!'. Contudo, Diego e Fabrício resolvem voltar para o grupo e todos continuam brincando o futebol do jeito dela (Diário de Campo, junho de 2018).

Esses gestos de resistência e transgressão produzidos por Manu,junto aos meninosno espaço da escola, podem ser pensados criticamente a partir das inquietações feministas, que com as diversas correntes teóricas, objetiva acabar, senão ao menos reduzir, as hierarquias entre meninos/homens e meninas/mulheres.

Na luta feminista para mudar e transformar as relações e situações de desigualdade entre homens e mulheres, independentemente de qualquer corrente feminista reconhece-se que existe uma causa social e cultural para a condição de subordinação das meninas e mulheres. (BANDEIRA, 2008)

Por certo, a crítica feminista vai de encontro com os movimentos criativos de Manu. Eles, nos impulsionamarefletir sobre as mudanças nas relações sociais de gênero que, historicamente, baseiam-se numa supremacia masculina que subjuga o feminino distinguindo atividades, comportamentos e corpos.

É imprescindível entender aquique existe uma diferença estrutural entre a infância feminina e a infância masculina; a menina, especialmente a pobre, é tida como não-elaborada e inferior, por isso a ela também é possível transgredir algumas normativas impostas aos meninos, representantes do poder. (ABRAMOWICZ, 1995) Contudo, na contemporaneidade, com o crescimento da articulação das perspectivas feministas na sociedade, nos espaços público e privado, precisamos cada vez mais aprofundar essa discussão.

Ao brincar de jogar futebol com os meninos, criativamente ela produz um ajuste secundário, "modelo de jogo" como um subsistema do sistema "padrão de futebol profissional", sendo este, um subsistema do sistema "cultura de jogo", que por sua vez, é 
subordinado ao jogo. O fato dos meninos se sentirem incomodados com as modificações das regras que estavam acostumados e com o suposto "controle" da menina sobre seus desejos e corpos, gera uma tensão necessária para que se possa pensar como as experiências articuladas pelas ideias sexistas e machistas vão estruturando as relações entre os gêneros.

As culturas infantis são articuladas em função das próprias brincadeiras na organização interna dos grupos infantis. Dentro deles, meninos e meninas podem praticar a solidariedade, o respeito às regras ou sua transgressão, numa relação de interação e em função da cultura da sociedade. (FERNANDES, 2004) No interior das culturas infantis as crianças "criam outras lógicas, novos cenários, mudam formas, personagens, enredos, e assim, produzem outros sentidos com a realidade, reinventando os sentidos propostos" (ORIEL PEREIRA; SANTIAGO, 2018, p. 105), e porque não dizer, também disputam entre si esse "território do brincar". Diante desta perspectiva, meninas e meninos ora legitimam os usos de alguns brinquedos e atitudes comportamentais ora não os reconhecem impondo obstáculos, estabelecendo limites aos participantes.

É preciso ressaltar que o interesse pelo entendimento dos mecanismos que estruturam a dominação masculina não significa, precisamente, que a preocupação esteja voltada para como acontece a opressão das mulheres e meninas. É preciso ter consciência que a dominação sentencia a maneira como homens e meninos e como as mulheres e meninas são representados, construídos e, por fim, organizam suas relações sociais. Outro ponto é entender o que é e como se dá a identidade pessoal e a subjetividade, as formas psíquicas de individuação, são consequência da posição/ lugar social que ocupamos cotidianamente no cerne das relações de dominação e de gênero. (APFELBAUM, 2009; MATHIEU, 1991)

Tomando o pensamento de Brah (2006), as relações de poder entre homens e mulheres são vistas como a principal dinâmica da opressão das mulheres, elas dependem de aspectos subjetivos e de outros elementos como a articulação referentes à raça, classe social, gênero, sexualidade que estão dentro de um projeto de sociedade elaborado pela lógica colonial eurocêntrica. De fato, as visões de mundo apresentam-se desiguais e são posicionadas assim como um fator culminante dessas condições sociais permitindo ou não que determinados grupos acessem lugares de cidadania. Por isso, se faz necessário analisar a localização dos grupos nas relações de 
poder, levando em conta os marcadores sociais de diferença como elementos dentro de construções múltiplas na estrutura social.

Como um exercício descolonizador, temos que partir das múltiplas condições que resultam desigualdades e hierarquias que localizam grupos subalternizados, voltando para a investigação de como as formasespecíficas de discursos sobre a diferença se constituem,são contestados, reproduzidos e (re)significados pelas experiências de meninas, mulheres, meninos e homens.

Nas infâncias existe uma diversidade de experiências e saberes das crianças que são ignoradas pelos adultos. "Ante a impossibilidade de adequar a sociedade centrada no adulto à criança, o adulto passa a educá-la". É na educação que "as relações de poder entre adulto e criança são cristalizadas" pela sociedade. (ROSEMBERG, 1976, p. 1466)

Contrapondo a esse adultocentrismo, "estamos nesse movimento de invenção, transgressão e descolonização, das pesquisas e das pedagogias. De luta, de rebeldias, de desobediência civil e epistêmica, aprendendo com as crianças e os/as jovens a não nos deixar dobrar". (MACEDO, et al, 2006, p. 48) Portanto, infere-se que não cabe, nos espaços educativos, sistemas de dominação que rejam as relações horizontais que as crianças estabelecem, uma vez que as crianças têm o direito de estar livre de qualquer amarra que as impedem de experienciar a infância em sua plenitude.

Nos processos de construção dos significados através da interação, a sociedade institui aos sujeitos como eles(as) devem ser, e torna esse dever como algo "natural" e "normal". Como por exemplo, a cor azul para os meninos e cor rosa para as meninas, a brincadeira e os brinquedos distintos para meninas e para os meninos:

Figura 1 - Gênero e poder

Nota: Desenhada pela cartunista Laerte Coutinho, promovendo críticas às amarras de gênero na infância.

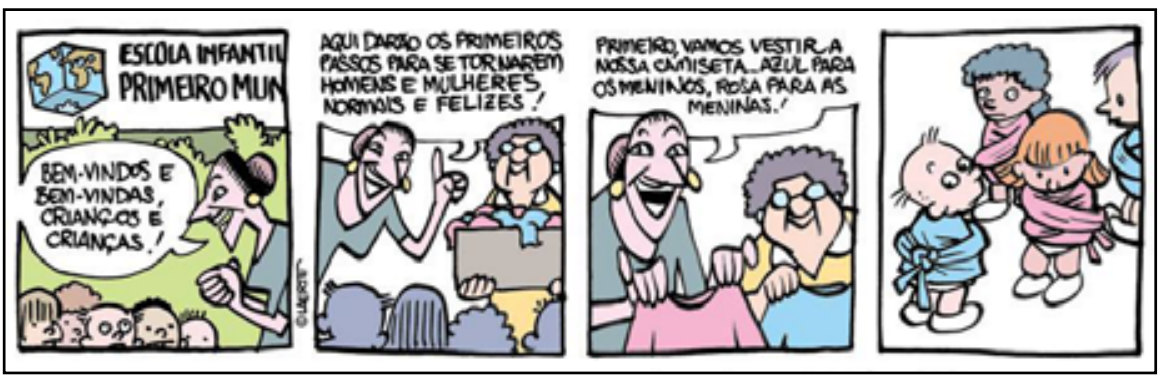

Fonte: Disponível em: https://acasadevidro.com/tag/laerte-coutinho/. Acesso em: 28 jun. 2018. 
Essa tirinha com o título "Escola Infantil Primeiro Mundo" traz o desenho do planeta em formato de quadrado, uma menção a forte presença do conservadorismo na sociedade moderna. Sua narrativa mostra uma mulher com brincos e penteado em coque, dizendo ao grupo infantil: "Bem-vindos e bem-vindas, crianços e crianças!".

O termo "crianços" nos chama a atenção para o sexismo linguístico que legitima ser "natural" expressar-se universalmente no masculino, quando na realidade essa convenção traz elementos que refletem o androcentrismo no qual a sociedade está mergulhada "[...] pela simples razão de que temos sempre visto dessa maneira, e isso faz com que nos pareça ser o 'natural' e por isso passamos a considerá-lo como universal e eterno [...]". (MORENO, 1999, p. 36) Nesse contexto, outra mulher também é representada carregando uma caixa com roupas nas cores azuis e rosas, reforçando a crítica sobre a distinção e imposição social aos gêneros.

As falas da primeira mulher: "Aqui darão os primeiros passos para se tornarem homens e mulheres normais e felizes!" e, logo depois, "Primeiro vamos vestir a nossa camiseta azul para meninos e rosa para meninas!", sintetiza o quanto essas noções estereotipadas ainda constroem padrões de identidades, comportamentos, produzem estigmas e aprisiona os sujeitos.

Acerca da questão de gênero e poder que delineia pressupostos ou rótulos, criados sobre características de grupos para moldar padrões sociais. No âmbito da educação infantil, esse processo marca o controle dos sentimentos, a expressão corporal, as habilidades e os modelos cognitivos das crianças. Essas práticas e discursos, atrelados as expectativas culturais da nossa sociedade, tornam-se uma forma de constituir masculinidades e feminilidades; "paraque as crianças 'aprendam', de maneira muito prazerosa e mascarada, a comportar-se como 'verdadeiros' meninos e meninas". (VIANNA; FINCO, 2009, p. 273)

Algo que determina, como destaca Araujo (2018, p. 10), "a formação compulsória de uma identidade de gênero hegemônica, visando moldar o desejo dos corpos de acordo com a matriz da heterossexualidade, desde a mais tenra idade". Isto, é um projeto de civilidade, operado e enrijecido pela linguagem, que produz um conjunto de atributos, comportamentos e papéis associados a meninas e meninos.

Então, como criar outras possibilidades de existência em um processo que envolve as diferentes masculinidades e feminilidades, 
para além das mais variadas maneiras pelas quais constituímos nossos desejos, afetos e corpos?

Tendo em vista que as crianças exercem atividades diferentes das prescrições normativas do que devem fazer e ser, podemos observar no espaço da escola que seus gestos e movimentos dão diversas respostas às regras e valores sociais:

Saímos do parque e fomos até os bebedouros do pátio para tomarmos água fresca. Alguns meninos lavaram seus rostos, e num gesto rápido, brincaram de jogar água uns nos outros, o que acabou incitando outras criançasa participarem da "guerrinha de água"por alguns minutos, o que despertou a intervenção das auxiliares técnicas que fazem a inspeção escolar. Em seguida, voltamos para a sala de aula. Estamos no último horário do período escolar, então, sugeri a turma que ficássemos na sala fazendo o que quiséssemos. Uns foram até o cantinho da leitura, esticaram os tatames de módulos emborrachados coloridos e se colocaram a ler livros infantis. Outros resolveram conversar entre si e aproveitar para fazer desenhos em seus cadernos. Nesse momento, coloquei-me a explicar para algumas crianças o significado de algumas palavras que estavam nos livros, quando assim solicitado por eles(as). Chegado o momento de guardar os materiais e fechar as mochilas, despedi-me da turma, eles(as) foram saindo da sala. Contudo, a menina Eloá vem até mim, entregou um desenho, dizendo: "É para você. Tchau professor, até amanhã!". Dei um sorriso e agradeci. Ela sorriu e sai pela porta (Diário de Campo, junho de 2018).

Tomo os desenhos infantis enquanto artefatos culturais e documentos históricos, que "como verdade iconográfica, não é expressão de neutralidade ou do todo ali representado. É invenção, fantasia, guarda elementos da imaginação, [...] do cotidiano vivido e sentido pelas meninas e meninos" (GOBBI, 2014, p. 154), portanto, uma atividade criadora que carrega a complexidade das relações experienciadas na convivência entre diferentes sujeitos em sociedade.

Nesse sentido, entende-se que as crianças, ao produzirem desenhos, trazem as marcas de gênero, raça e classe social, uma vez que "ao desenharem traçam o mundo pelo seu olhar, sendo esse ato uma das formas de materialização simbólica das culturas infantis, trazendo para suas construções os conflitos existentes nos espaços em que convivem". (ORIEL PEREIRA; SANTIAGO, 2018, p. 102) Assim, trago a criação de Eloá como um ator e conheci- 
mento das crianças, mostrando o seu papel ativo na sociedade, desmistificando perspectivas que as pensam como seres passivos e receptores na sociedade.

Também como princípio de respeito, de cuidado e de reciprocidade, que explicita o quanto a relação entre crianças e professores(as) precisa ser livre das amarras coloniais e capitalistas que impedem a experiência da afetividadenos espaços da escola. Principalmente, trazendo para a cena social a legitimidade da participação das crianças em pesquisas que, com suas hesitações, silêncios, vozes, corpos, seus achados no revelar do enunciado, inscrevem suas percepções e indagações frente ao mundo.

Figura 2 - Meninas e meninos jogando futebol

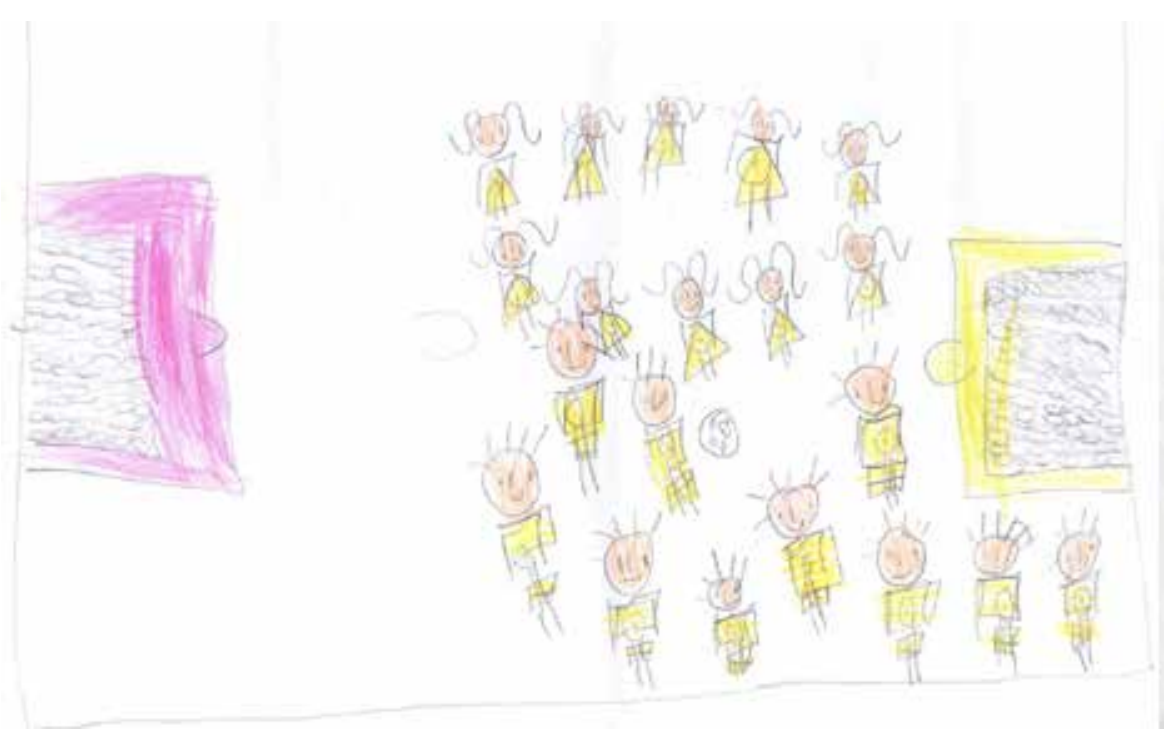

Reprodução de desenho feito por Eloá em papel branco, lápis preto e de cor, no retorno do parque à sala de aula.

Podemos verificar no desenho de Eloá que os traços, símbolos e cores das criações das crianças, nos permite pensar este momento da sociedade, com suas permanências e transformações históricas, sociais e culturais, e as marcas de gênero que articulam as relações sociais e as atividades de/para meninas/mulheres e meninos/ homens nos espaços sociais, público e privado.

Estaria ela protagonizando histórias que ainda tem pouca visibilidade, como uma lutadora na arena da vida?

A presença feminina no esporte e nas brincadeiras ditas masculinas não elimina, no entanto, a permanência de um padrão 
androcêntrico nas atividades esportivas legitimadas pela sociedade, seja pelas diferentes oportunidades que mulheres e homens têm desde o seu nascimento ou as referências veiculadas pelos diversos meios de comunicação.

O futebol enquanto marcador social que dissemina uma educação corporal fortemente diferenciada por gênero e desigual, como esporte é expressão da dominação masculina, da ordem vigente e das normas presentes na sociedade, portanto, generifica as brincadeiras nos espaços escolares, marcando a divisão sexual e maneira como essa separação organiza as relações. (ALTMANN, 2015; WENETZ, 2005)

Dentro desse quadro, os sistemas de feminilização e masculinização dos corpos, criam o imperativo do corpo branco, heterossexual, cisgênero. Esse modelo se assenta em um projeto racial de sociedade, de civilidade e de sexualidade.

No contexto brasileiro, esse ideal é marcado pela colonialidade e delineado no "desejo de nossas elites pela branquitude imaginada não apenas em termos cromáticos, mas, sobretudo, morais e de poder, da capacidade de autocontrole e domínio dos outros [...]". (MISKOLCI, 2012, p. 121) Assim, os(as) "estranhos(as)" em meio a essa naturalidade não passam despercebidos(as), pois lhe são conferidos atributos que o tornam diferente, resultando na sua marginalização no interior de uma coletividade.

É possível pensar aqui, em estigmas, como um atributo dado a um sujeito ou grupo em processos de diferenciação que são estabelecidos dentro de relações sociais. "O normal e o estigmatizado não são pessoas, e sim perspectivas que são geradas em situações sociais durante os contatos mistos, em virtude de normas não cumpridas que provavelmente atuam sobre o encontro". (GOFFMAN, 2004, p. 117)

Desse ponto de vista, os estigmas relacionados a gênero e aos comportamentos não convencionais, articulam questionamentos, tais como: "o que é normal e estranho para homem/mulher?". Isto se apresenta na vida social através de uma concepção excludente que determina a mulher com a expressão mais "masculinizada" a figura de "homem" e ao homem com expressões mais "feminilizada" a figura de "mulher", criando sistemas de nomeação jocosos e pejorativos. Contudo, como nos alerta Goffman (2004), as situações que envolvem estigmas são importantes para a observação e análise social em diferentes contextos e por diversos ângulos. 


\section{Considerações finais: entre movimentos de encaixe/ desencaixe das representações}

A naturalização de valores machistas hetero-patriarcais e as divisões binárias e dicotômicas criam abismos entre os gêneros. Porém, atualmente, no cotidiano da escola, quando as meninas e meninos brincam, suas potencialidades criativas e transgressoras fazem um movimento de encaixe/desencaixe nas representações que já conhecemos, revelando-nos um olhar parcial que desestabilizaa autoridade dessas construções culturais e sociais.

Se as culturas infantis sãoapropriaçõesda cultura mais ampla em que as crianças estão inseridas, elaspodem ser tomadas como tradução cultural, ou seja, como reprodução ou representaçãoque nega a originalidade ou a essência do suposto "modelo". Isto remonta aambivalência do discurso colonial - que repete, mas re-apresenta, e nessareapresentação provoca deslocamentos na arena de significação, pondo em ameaça aideia de normalização e fixação dos sentidos. (BHABHA, 2003) Em virtude que não há fixidez na cultura, e até mesmo os mesmos sinais podem ser apropriados, traduzidos e re-historicizados.

Assim, as meninas tensionam a supremacia masculina e as expectativas de gênero, afirmam-se no grupo infantil predominantemente formado por meninos. Elas dimensionam o jeito de ser e se relacionar, sendo líderes, jogadoras de futebol, ao mesmo tempo em que, através das brincadeiras, dinamizam e transformam regras e valores de conduta social resistindo juntos aos meninos. Dessa maneira, buscam a equidade entre os gêneros, produzem culturas que possibilitam mudanças sociais necessárias para a sociedade. Como um exemplo de experiência feminista, Manu, Eloá e tantas outras meninas e mulheres, com seus corpos e atitudes escancaram a diversidade e a diferença, trazendo outros olhares de forma que todas e todos sejamos beneficiadas(os) em liberdade e respeito. 


\title{
"She just wants to play her soccer": when girls play and tension the male supremacy and genre expectations alongside boys in the school space
}

\begin{abstract}
This article tries to make some considerations about the resistance and transgression gestures of 7-year-old girls against the chauvinist hetero-patriarchal imposition which demands certain behaviours, game execution and restrain the use of social areas by different people. It is a research carried out in the school, in the initial year of elementary education, based on the feminist thought and the study of children and childhood, aiming the expansion of our perceptions about peer culture generated by children whowith their actions, experiences, creations, inventions and movements tension the schemes of sexism and chauvinism present in the society.
\end{abstract}

Keywords: Gender relations. Feminism. Peer culture. Elementary education.

\section{"Ella sólo quiere jugar su fútbol": cuando niñas brincan y tensionan la supremacia masculina y las expectativas de género juntos a los niños en el espacio de la escuela}

\begin{abstract}
Resumen: Este artículo busca realizar algunas reflexiones sobre los gestos de resistencia y transgresiones de niñas de 7años de edad contra las normatizaciones machistas hetero-patriarcales que impone determinadas posturas, ejecución de juegos y restringe el uso de espacios sociales para los diferentes sujetos. Se trata de una investigación realizada enlaescuela, en los años iniciales de laeducación primaria, construidacon base enelpensamiento feminista y los estúdios de lniño y de la infancia, buscando laampliación de nuestras percepciones acerca de las culturas de la infância producidas por los niños que consusprácticas, experiencias, creaciones, invenciones y movimentos tensan las tramas delsexismo y el machismo presentes en la sociedad.
\end{abstract}

Palabras clave: Relaciones de género. Feminismo. Culturas de lainfancia. Educación primaria.

\section{Referências}

ABRAMOWICZ, Anete. A menina repetente. Campinas: Papirus, 1995.

ADICHIE, Chimamanda Ngozi. Sejamos todos feministas. São Paulo: Companhia das Letras, 2008.

ALTMANN, Helena. Educação física escolar: relações em jogo.

São Paulo: Cortez, 2015. (Coleção Educação \& Saúde, v. 11)

ARAUJO, Rubenilson Pereira de. Brincadeiras de masculinidades, (re) configurações familiares e relacionamento interrelacional em menino brinca com menina?, de Regina Drummond. Humanidades \& Inovação, [S. l.], v. 5, n. 3, p. 9-17, feb. 2018.

APFELBAUM, Erika. Dominação. Trad. Vivian Aranha Saboia.

In: HELENA, Hirata. et al. (org.). Dicionário crítico do feminismo.

São Paulo: Editora UNESP, 2009, p. 76-79. 
BANDEIRA, Lourdes. A contribuição da crítica feminista à ciência. Estudos Feministas, Florianópolis, v. 16, n. 1, p. 207-230, jan./abr. 2008.

BHABHA, Homi K. O pós-colonial e o pós-moderno: a questão da agência. In: BHABHA, Homi K. O localda cultura. Tradução Myriam Ávila, Eliana Lourenço de Lima Reis e Gláucia Renate Gonçalves. Belo Horizonte: UFMG, 2003. p. 239-273.

BRAH, Avtar. Diferença, diversidade, diferenciação. Cadernos Pagu, Campinas, SP, n. 26, p. 329-376, 2006.

BRASIL. Conselho Nacional de Saúde. Resolução n 466, de 12 de dezembro de 2012. Aprova normas regulamentadoras de pesquisas envolvendo seres humanos. Diário Oficial da União: seção 1, Brasília, DF, n. 12, p. 59, 13 jun. 2013.

BRASIL. Casa Civil. Lei no 8.069, de 13 de julho de 1990. Dispõe sobre o Estatuto da Criança e do Adolescente e dá outras providências. Diário Oficial da União: Brasília, DF, 16 jul. 1990. Disponível em: http://www. planalto.gov.br/ccivil_03/leis/18069.htm. Acesso em: 6 out. 2019.

CORSARO, William Arnold. Reprodução interpretativa: as crianças participam coletivamente na sociedade. In: CORSARO, William Arnold. Sociologia da Infância. Trad. Lia Gabriele Regius Reis. Porto Alegre: Artmed, 2011, p. 31-56.

FERNANDES, Florestan. As trocinhas do Bom Retiro: contribuição ao estudo folclórico e sociológico da cultura e dos grupos infantis. In: FERNANDES, Florestan. Folclore e mudança social na cidade de São Paulo. São Paulo: Martins Fontes, 2004, p. 195-315.

FERNANDES, Florestan. Sociedade: Luta de raças e de classes. Teoria e Debate. São Paulo, n. 2, p. 1-6, mar. 1998.

GEERTZ, Clifford. A interpretação das culturas. Rio de Janeiro: LTC, 2008.

GOBBI, Márcia Aparecida. Mundos na ponta do lápis: desenhos de crianças pequenas ou de como estranhar o familiar quando o assunto é criação infantil. Linhas Críticas, Brasília, DF, v. 20, n. 41, p. 147-165, jan./abr. 2014.

GOFFMAN, Erving. Estigma: notas sobre a manipulação da identidade deteriorada.Trad. Mathias Lambert. São Paulo: Coletivo Sabotagem, 2004. p. 117-118.

GOFFMAN, Erving. Asytums. Garden City: NJ: Anchor, 1961.

IANNI, Octavio. Octavio Ianni: o preconceito racial no Brasil. Estudos Avançados, São Paulo, v. 18, n. 50, p. 6-20, jan./abr. 2004.

INFANTINO, Agnese; ZUCCOLI, Franca. Superando a distância entre o pensamento e a prática. Pátio Educação Infantil, Porto Alegre, n. 46, p. 44-48, jan. 2016. 
LÚDKE, Menga. Professor, seu saber e sua pesquisa. Educação \& Sociedade, Campinas, SP, ano XXII, n. 74, p. 77-96, abr. 2001.

MACEDO, Elina Elias de; SANTIAGO, Flávio; SANTOS, Solange Estanislau dos; FARIA, Ana Lúcia Goulart de. Infâncias e descolonização: desafios para uma educação emancipatória. Crítica Educativa, São Carlos, v. 2, p. 38-50, 2017.

MATHIEU, Nicole-Claude. L'anatomie politique. Paris: Côté-femmes, 1991. p. 131-225.

MISKOLCI, Richard. O desejo da nação: masculinidade e branquitude no Brasil de fins do XIX. São Paulo: Annablume, 2012, p. 120-121.

MORENO, Montserrat. Como se ensina a ser menina. São Paulo: Moderna, 1999, p. 39-40.

ORIEL PEREIRA, Artur; SANTIAGO, Flávio. Matizes e nuances que desenham omundo: culturas infantis e as marcas das relações de gênero, raça e classe social. In: $56 .{ }^{\circ}$ Congreso de Americanistas, 2018, Salamanca. Estudiossociales: 56. ${ }^{\circ}$ CongresoInternacional de Americanistas / Manuel Alcántara, Mercedes García Montero y Francisco Sánchez López (coord.). Salamanca: Ediciones Universidad de Salamanca,2018. v. 12. p. 99-107.

RINALDI, Carla. Diálogos com ReggioEmilia: escutar, investigar e aprender. São Paulo: Paz e Terra, 2012.

ROSEMBERG, Fúlvia. Educação: para quem? Ciência e Cultura, Campinas, v. 12, n.28,p. 1466-1471, dez., 1976.

SANTOS, Lucíola Licínio de Castro Paixão. Dilemas e perspectivas na relação entre ensino e pesquisa. In: ANDRE, Marli. O papel da pesquisa na formação e na prática dos professores. Campinas, SP, 2012. p. 11-25.

SEVERINO, Antonio Joaquim. Metodologia do trabalho científico. São Paulo: Cortez, 2007.

VIANNA, Claudia; FINCO, Daniela. Meninos e meninas na Educação Infantil: uma questão de gênero e poder. Cadernos Pagu, Campinas, SP, n. 33, p. 265-283, jul/dez. 2009.

WENETZ, Ileana. Gênero e sexualidade nas brincadeiras do recreio. $204 \mathrm{f}$. Dissertação (Mestrado em Ciência do Movimento Humano) - Escola de Educação Física, Universidade Federal do Rio Grande do Sul, Porto Alegre, 2005.

Submetido: 07 de julho de 2018

Aceito: 08 de julho de 2019 